\title{
PENGARUH PENGGUNAAN PENYALUT BIOBLEND PS/PCL TERHADAP PELEPASAN ZAT AKTIF UREA GRANUL
}

\author{
Salman ${ }^{1,2}$, Febriyenti ${ }^{1}$, Akmal D. ${ }^{* 1}$ \\ ${ }^{1}$ Faculty of Pharmacy, University of Andalas, Padang 25163, West Sumatra, Indonesia. \\ ${ }^{2}$ Department of Pharmacy, Faculty of Sciences, Syiah Kuala University, \\ Banda Aceh, Indonesia \\ Email: akmaldjamaan@yahoo.co.id
}

\begin{abstract}
The most widely used surfactant is an anionic surfactant which is synthesized from petroleum namely Linear Alkylbenzene sulphonate (LABS). Methyl Ester Sulfonate which is currently being developed. Surfactant can produced from palm oil methyl ester via sulfonation sulfonate. When in this research using sodium metabisulphite. The aims of this work is to synthesize Methyl Ester Sulfonate surfactant from Palm Oil Methyl Ester using Sodium Metabisulphite and a catalyst Calcium Oxide. The effects of time and the mole ratio are also investigated. Sulfonation process carried out in 4, 5, 6 hours with mole ratio of 1: $0,5,1: 1,1: 1,5$, temperature of $80^{\circ} \mathrm{C}$ and with stirring speed of $450 \mathrm{rpm}$. It haven been found that the surfactant produced has density of $\left(0.89490 \mathrm{~g} / \mathrm{cm}^{3}-0.89545 \mathrm{~g} / \mathrm{cm}^{3}\right)$, viscosity $(2.0323 \mathrm{cP}-2.1329 \mathrm{cP}), \mathrm{pH}(2,03-$ $2,48)$, surface tension $(32.60 \mathrm{mN} / \mathrm{m}-33.60 \mathrm{mN} / \mathrm{m})$, interfacial tension $(30.45 \mathrm{mN} / \mathrm{m}-30.94$ $\mathrm{mN} / \mathrm{m})$, and the stability emulsion $(59.17 \%-89,17 \%)$.
\end{abstract}

Keywords: bioblend, coating, urea, slow-release fertilizer.

\section{PENDAHULUAN}

Saat ini penggunaan pupuk lepas lambat atau pelepasan terkontrol merupakan caraefektif untuk memecahkan beberapa permasalahan dari penerapan pupuk konvensional ${ }^{[1]}$. Pupuklepas lambat bertujuan untuk meningkatkan efisiensi penggunaan hara oleh tanaman dan meminimalkan kehilangan unsur hara, sehingga dapat mengurangi pencemaran lingkungan dan masalah kesehatan yang sering dikaitkan dengan manajemen pemupukan. Pupuk konvensional yang disebarkan pada tanaman tidak semua dapat diserap oleh tanaman, dimana efisiensi pemupukan untuk urea hanya sekitar 30-50 $\%$, yang selebihnya akan mengalami degradasi atau terbawa hanyut oleh air ${ }^{[2,3]}$. Penggunaan pupuk lepas lambat memiliki beberapa keuntungan seperti meningkatkan efisiensi, mengurangi hilangnya pupuk oleh air hujan atau air irigasi, memberikan pelepasan berkelanjutan untuk waktu yang lebih lama, menghemat konsumsi pupuk dan meminimalisasi pencemaran ${ }^{[4,5]}$.

Proses pelepasan hara atau nutrisi pupuk yang disalut polimer seperti yang telah dijelaskan oleh Kobayashi et al., (1997) dan Shaviv, (2001). Proses pelepasan terjadi dalam beberapa tahap yaitu; Tahap pertama dimana air akan menembus melalui lapisan polimer. Tahap kedua, setelah air menembus inti urea maka akan terjadi pelarutan inti dari urea, yang akan menyebabkan terbentuknya tekanan inner pada inti urea. Lapisan penyelut terjadi pembengkakan dan memperbesar pori difusi. Pada tahap ketiga, nutrisi dilepaskan melalui difusi karena didorong oleh gradien konsentrasi di lapisan, atau melalui aliran massa yang didorong oleh gradien tekanan, bisa juga melalui kombinasi keduanya $^{[6,7]}$.

Manfaat maksimal dari urea lepas lambat ketika nutrisi yang dilepaskan dalam jangka waktu yang cukup panjang dan nutrisi yang dilepaskan harus sesuai 
dengan periode serapan nutrisi oleh $\operatorname{tanaman}^{[7]}$.

Faktor efisiensi polimer penyalut juga menjadi masalah pada penyalutan urea karena tingkat kompatebilitas urea dengan bahan polimer sintetis maupun biopolimer rendah, kompatibilitas yang baik akan meningkatkan efisiensi pelapisan polimer pada ureadan memperpanjang waktu pelepasan nutrisi dari urea granul, selain itu ketebalan dan kekuatan film penyalut sangat mempengaruhi tingkat pelepasan dan pola pelepasan $^{[8,9]}$.

Tujuan penelitian ini untuk mempelajari pengaruh penyalutan pupuk urea mengunakan penyalut bioblend polistiren terhadap tingkat pelepasan zat aktif urea granul.

\section{METODOLOGI PENELITIAN}

\section{Bahan dan Alat}

Alat: Hotplate magnetik stirer (Thermo Scientific), spektrofotometer UV-Vis (UV1700 PharmaSpec), timbangan analitik (Shimadzu AUX 220), Fourier transform infrared spectroscopy (PerkinElmer), $\mathrm{pH}$ meter (Thermo Scientific),oven, Spray gun dan pompa, coating pan, mikrometer digital (Mitutoyo), alat-alat gelas dan peralatan lainya

Bahan : Polistiren, polikaprolakton (Aldrich Chemical), urea granul (PT. Pupuk Sriwijaya, Indonesia) diameter $2 \mathrm{~mm}$, kloroform (Merck), Alkohol (Merck), reagen Erlich, aqua DM.

\section{Preparasi Urea Granul}

Sebelum dilakukan penyalutan semua urea granul dicuci menggunakan kloroform, kemudian dikeringkan dalam oven pada suhu 50-60 ${ }^{\circ} \mathrm{C}$. Kemudian urea disortir dengan ukuran 1-2 mm sehingga didapatkan ukuran urea yang seragam.

\section{Pembuatan Larutan Penyalut}

Polistiren dengan jumlah sesuai dengan Tabel 1, dilarutkan dengan $50 \mathrm{~mL}$ kloroform, untuk prosedur penyalutan menggunakan bioblend polistiren/ polikaprolakton dengan perbandingan polistiren : polikaprolakton, $2: 1,3: 1,4: 1,5: 1,6: 1$, untuk formula dengan perbandingan 2:1 dibuat dengan mencampurkan 1 gram polistiren dengan 0,5 gram polikaprolakton kemudian dilarutkan dalam $50 \mathrm{~mL}$ kloroform. Larutan tersebut diaduk menggunakan magnetik stirrer dengan kecepatan 380 rpm selama 10 menit..

\section{Proses Penyalutan}

Urea granul sebanyak 25 gram dimasukkan ke dalam coating pan, larutan penyalut dimasukkan dalam wadah larutan pada spray gun. Kemudian urea granul disemprot dengan larutan penyalut, kecepatan putar coating pan disesuaikan, dan suhu diatur 60-70 ${ }^{\circ} \mathrm{C}$.selanjutnya dilakukan pengeringan menggunakan oven pada suhu $70-80{ }^{\circ} \mathrm{C}$ selama 1 jam.

\section{Pengukuran Distribusi Ukuran Granul}

Pengukuran ukuran granul dilakukan dengan teknik digital menggunakan software imagej versi $1.48 \mathrm{v}$, pengambilan foto untuk pengukuran dilakukan dengan menggunakan teknik fotografi makro menggunakan kamera DSLR Canon 1100D yang dilengkapi dengan lensa makro Canon EF-S 60mm f/2.8 Macro USM Fixed Lens. Data ukuran granul yang didapat dari pengukuran digital dengan software imageJ kemudian data diolah dengan menggunakan software OriginPro.

\section{Analisis Fourier Transform Infrared Spectroscopy (FTIR).}

Evaluasi ini dilakukan untuk menentukan kemungkinan interaksi antara komponenkomponen bahan penyalut dan juga dengan urea granul.Analisis ini dilakukan menggunakan alat FTIR PerkinElmer tipe Universal ATR

\section{Pengukuran Ketebalan Film}

Pengukuran ketebalan film dilakukan dengan menggunakan alat mikrometer digital. Lapisan penyalut yang telah dilepas dari urea granul dipasang pada alat micrometer digital sehingga akan terbaca ketebalan film pada layar alat mikrometer. 


\section{Persen Penyalutan}

Efisiensi penyalutan dapat ditentukan dengan melarutkan produk dengan massa yang diketahui, $\mathrm{M}_{\text {total }}(\mathrm{g})$ ke dalam $100 \mathrm{~mL}$ air suling pada suhu kamar $\left( \pm 24{ }^{\circ} \mathrm{C}\right)$. Setelah pupuk terlarut sempurna, selanjutnya disaring menggunakan kertas saring, maka akan peroleh residu (polimer penyalut) yang terlepas dari urea. Residu kemudian dicuci dengan air suling lalu dikeringkan pada suhu $120{ }^{\circ} \mathrm{C}$ selama kurang lebih 4-6 jam, kemudian ditimbang, $\mathrm{M}_{\text {polimer }}(\mathrm{g})$. Efisiensi peyelutan dihitung dengan persamaan :

$$
\% \text { Coating }=\frac{M \text { residu polimer }(g)}{M \text { total }(g)} \times 100
$$

Dimana: \% coating adalah persentase polimer yang disalutkan pada urea granul, $\mathrm{M}_{\text {polimer }}$ adalah massa residu polimer dan $\mathrm{M}_{\text {total }}$ adalah massa total ${ }^{[10,11]}$.

\section{Uji pelepasan dan penentuan kadar urea}

\section{Uji pelepasan pada media air}

Pada evaluasi ini 1 gram urea yang sudah disalut bioblend dilarutkan dalam $500 \mathrm{ml}$ air suling. Sampel air diambil pada setiap 1, 3, 6, 12 dan 24 jam, kemudian dianalisa dengan menggunakan spektrofotometer [5,12-14].

\section{Uji pelepasan pada media tanah}

Pada evaluasi ini ditimbang 100 gram tanah kering. Kemudian ditempatkan ke dalam corong kaca yang telah diberi alas kertas saring.ditimbang 3 gram sampel formula 2, 3 dan urea yang tidak disalut. Sampel selanjutnya ditanam dalam tanah kering pada corong kaca yang ditempatkan dalam botol kaca dengan tinggi $27 \mathrm{~cm}$. Tanah dibasahkan dengan air suling sebanyak $20 \mathrm{~mL}$, dengan kecepatan aliran air (flux) $5 \mathrm{~mL} /$ menit. Dimana curah hujan tertinggi daerah Sumatra Barat mencapai $4000 \mathrm{~mm} /$ Tahun, atau sama dengan 7,71 $\mathrm{mL}$ per menit/meter ${ }^{2}[15]$. Sampel diambil setiap hari sampai hari ke 10. Pengukuran absorbansi dari sampel dilakukan menggunakan spektrofotometer.

\section{Uji pelepasan pada media lumpur}

Pada evaluasi ini ditimbang 100 gram lumpur yang diambil dari sawah, kemudian lumpur tersebut ditempatkan dalam gelas kimia 1000 $\mathrm{mL}$. Selanjutnya ditimbang 2 gram sampel formula 2, 3 dan urea tidak disalut. Sampel formula tersebut selanjutnya ditanam dalam lumpur. Kemudian ditambahkan $500 \mathrm{~mL}$ air suling.sampel air dikoleksi dan diukur absorbansinya. Sampel diambil setiap hari sampai hari ke 10. Pengukuran absorbansi dari sampel dilakukan menggunakan spektrofotometer.

\section{Penentuan kadar urea}

Penentuan kadar urea menggunakan metode spektrofotometri dan reagen pembentuk warna para-Dimethyl amino benzaldehyde (DMAB). Menurut reaksi Ehrlich(DMAB) dapat bereaksi dengan urea membentuk warna lemon kelly (yellow-green color) yang akan menyerap cahaya tampak pada $420 \mathrm{~nm}$, warna yang terbentuk akan stabil setelah 10 menit[13,16-18]. Larutan reagen dibuat dengan melarutkan 2 gram DMAB dalam 95\% etil alkohol $(90 \mathrm{ml})$ dan asam klorida pekat $(10 \mathrm{ml})$. Untuk menentukan jumlah urea, kurva kalibrasi dibuat dengan larutan standar dengan konsentrasi 5, 10, 20, 40, 60, $100,400,600,800,1000$ dan 1200 ppm.

\section{HASIL DAN DISKUSI}

\section{Distribusi Ukuran Granul dan Ketebalan Film}

Hasil pengukuran distribusi ukuran granul, diketahui granul terdistribusi dengan ukuran berkisar antara 1,5 milimeter sampai 3 milimeter (Gambar 1). Hasil pengukuran ketebalan film penyalut, diketahui ketebalan film penyalut tiap formula berbeda-beda, ketebalan mulai dari rentang 0,125 milimeter sampai 0,196 milimeter (Tabel 1).

Tabel 1.Ketebalan film penyalut.

\begin{tabular}{|c|c|c|}
\hline No. & $\begin{array}{c}\text { Kode } \\
\text { Formula }\end{array}$ & $\begin{array}{c}\text { Ketebalan film } \\
\text { rata-rata(mm) }\end{array}$ \\
\hline 1 & F1 & 0,150 \\
\hline 2 & F2 & 0,158 \\
\hline 3 & F3 & 0,193 \\
\hline 4 & F4 & 0,190 \\
\hline 5 & F5 & 0,196 \\
\hline
\end{tabular}




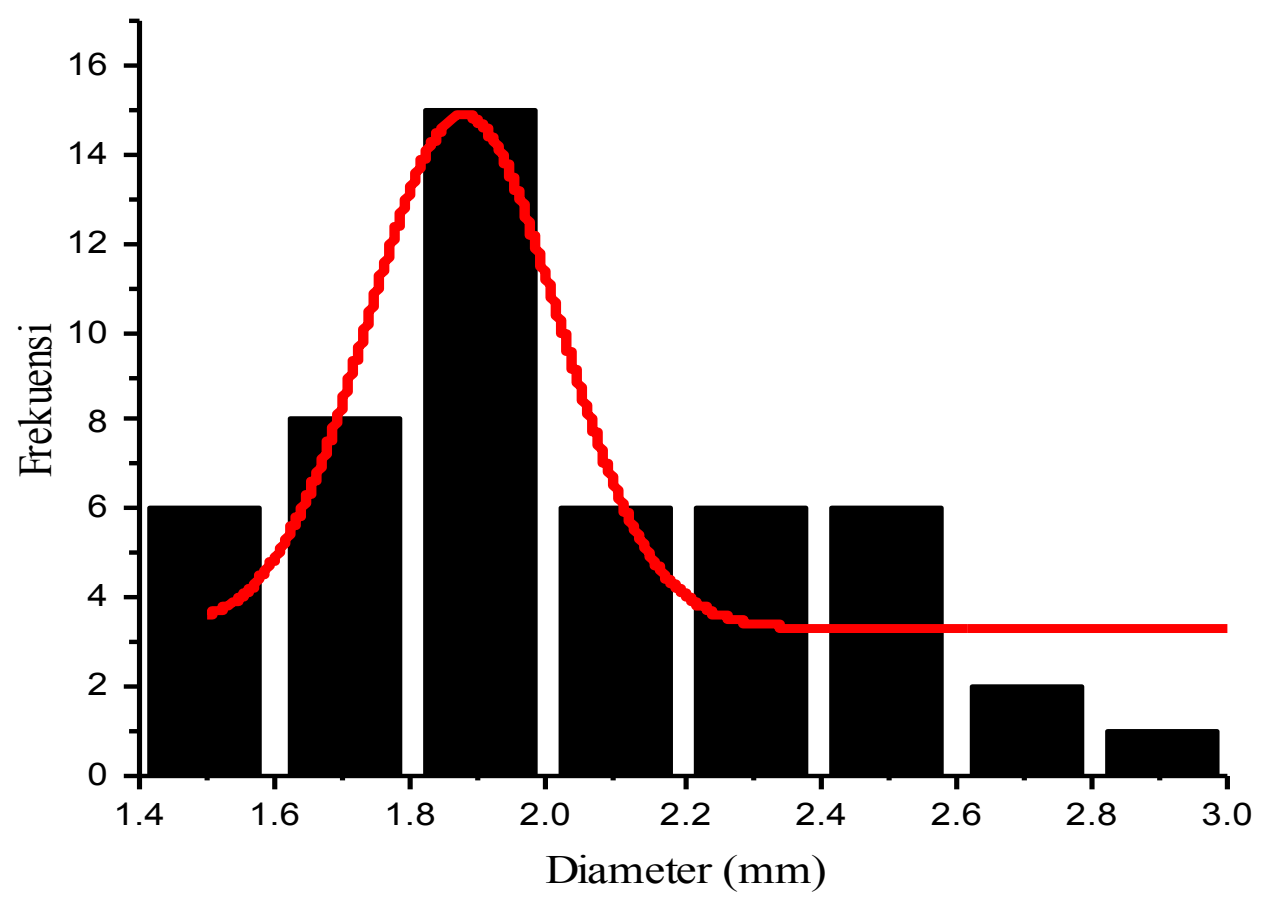

Gambar 1. Kurva distribusi ukuran granul.

\section{Analisa Fourier Transform Infrared Spectroscopy (FTIR)}

Hasil analisi FTIR pada sampel menunjukkan kemiripan spektrum FTIR dari sampel urea tanpa penyalutan.Puncak 3429 dan $3336 \mathrm{~cm}^{-1}$ urea biasa dan sampel formula, merupakan vibrasi rengangan asimetris dan simetris $\mathrm{NH}_{2}$.

Pada semua sampel terlihat puncak pada $3256 \mathrm{~cm}^{-1}$, yang merupakan vibrasi $\mathrm{OH}$ dari air yg diserap. Puncak pada $1672 \mathrm{~cm}^{-1}$ merupakan karbonil (CO) dan puncak 1589 $\mathrm{cm}^{-1}$ merupakan vibrasi tekuk N-H dan vibrasi rengangan $\mathrm{C}-\mathrm{H}$, semua puncak dari sampel urea biasa dan sampel formula terlihat sangat mirip ini menunjukkan bahwa tidak terjadi perubahan ${ }^{[11,16,19,20]}$.

\section{Persen Penyalutan}

Semakin besar masa polimer penyalut dalam larutan penyalutan, maka semakin besar persen penyalutan. Konsentrasi larutan akan sangat berpengaruh pada pengoperasian alat dan mekanisme pertumbuhan film penyalut pada permukaan urea. Pada Tabel 2., menunjukkan semakin besar massa penyalut maka persen penyalutan akan semakin besar.

Tabel 2. Pengaruh jumlah polimer penyalut terhadap persen penyalutan.

\begin{tabular}{|c|l|c|c|c|}
\hline No. & Formula & $\begin{array}{c}\text { Bobot awal } \\
\text { sampel (gram) }\end{array}$ & $\begin{array}{c}\text { Bobot residu } \\
\text { polimer (gram) }\end{array}$ & Persen penyalutan (\%) \\
\hline 1 & Formula 1 & 10 & 0.5 & 5,0 \\
\hline 2 & Formula 2 & 10 & 0.71 & 7.1 \\
\hline 3 & Formula 3 & 10 & 0.85 & 8.5 \\
\hline 4 & Formula 4 & 10 & 0.9 & 9,0 \\
\hline 5 & Formula 5 & 10 & 1,0 & 10 \\
\hline
\end{tabular}




\section{Profil Pelepasan Urea pada Media Air}

Profilpelepasan urea salut bioblendpolistiren pada media air suling suhu ruangan menunjukkan dalam waktu 24 jam, urea yang terlepas lebih dari $80 \%$, hanya formula 2 dan 3 yang pelepasan urea kurang dari $80 \%$. Mungkin hal ini disebabkan film penyalut yang terbentuk tidak terlalu kuat sehingga tidak sangup menahan dorongan dari inti granul urea sehingga menyebabkan lapisan film penyalut pecah. Maka dengan demikian, semua formula urea salut bioblend polistiren tidak efisien untuk diaplikasi pada media air.

Profil kinetika pelepasan pada media air, untuk formula 2, 3, 4 dan 5 mengikuti model kinetika pelepasan orde 0 dan model kinetika pelepasan Korsemeyer-peppas.Dimana nilai koefisien regresi (r) untuk kedua model kinetika pelepasan tersebut paling mendekati, dimana nilai $\mathrm{r}$ untuk formula $2,3,4$ dan 5 dengan menggunakan model kinetika pelepasan orde 0 yaitu berturut-turut sebesar 0,$9992 ; 0,9995 ; 0,9997 ; 0,9992$. Sedangkan nilai $\mathrm{r}$ untuk formula $2,3,4$ dan 5 dengan menggunakan model kinetika pelepasan Korsemeyer-peppas yaitu berturut-turut sebesar 0,9989; 0,9993; 0,9996; 0,9981. Pelepasan urea mengikuti model kinetika orde nol berarti pelepasan urea terjadi secara konstan dari awal sampai akhir.

Tabel 3.Pelepasan urea terhadap waktu untuk setiap formula pada media air destilasi.

\begin{tabular}{|l|c|c|c|c|c|c|}
\hline \multirow{2}{*}{ Sampel formula } & \multicolumn{5}{|c|}{ Persentase pelepasan urea dalam tiap jam (\%) } \\
\cline { 2 - 7 } & 0 & 1 & 3 & 6 & 12 & 24 \\
\hline Formula 1 & 0 & 6 & 17 & 37.6 & 75.9 & 95 \\
\hline Formula 2 & 0 & 2.7 & 7.7 & 17.3 & 34.2 & 66 \\
\hline Formula 3 & 0 & 3.2 & 9.5 & 20.4 & 37.8 & 76 \\
\hline Formula 4 & 0 & 3.4 & 10 & 21.2 & 40.1 & 80 \\
\hline Formula 5 & 0 & 4 & 11 & 25.6 & 47.0 & 96 \\
\hline
\end{tabular}

Tabel 4.Pelepasan urea terhadap waktu untuk formula $2,3 \&$ urea tidak disalut pada media tanah,

\begin{tabular}{|l|c|c|c|c|c|c|c|c|c|c|c|}
\hline \multirow{2}{*}{$\begin{array}{c}\text { Sampel } \\
\text { formula }\end{array}$} & \multicolumn{10}{|c|}{ Persentase pelepasan urea dalam tiap hari (\%) } \\
\cline { 2 - 13 } & 0 & 1 & 2 & 3 & 4 & 5 & 6 & 7 & 8 & 9 & 10 \\
\hline Formula 2 & 0 & 2.0 & 4.0 & 5.5 & 7.1 & 9.2 & 10.4 & 12.5 & 14.0 & 17.0 & 18.3 \\
\hline Formula 3 & 0 & 3.0 & 5.4 & 8.0 & 11.0 & 14.0 & 17.0 & 19.4 & 23.0 & 24.9 & 28.0 \\
\hline $\begin{array}{l}\text { Urea tanpa } \\
\text { penyalut }\end{array}$ & 0 & 31.0 & 61.0 & 90.0 & 90.1 & 90.1 & 90.1 & 90.1 & 90.1 & 90.1 & 90.1 \\
\hline
\end{tabular}

Tabel 5. Pelepasan urea terhadap waktu untuk formula $2,3 \&$ urea tidak disalut pada media lumpur.

\begin{tabular}{|l|c|c|c|c|c|c|c|c|c|c|c|}
\hline \multirow{2}{*}{$\begin{array}{c}\text { Sampel } \\
\text { formula }\end{array}$} & \multicolumn{10}{|c|}{ Persentase pelepasan urea dalam tiap hari (\%) } \\
\cline { 2 - 14 } & 0 & 1 & 2 & 3 & 4 & 5 & 6 & 7 & 8 & 9 & 10 \\
\hline Formula 2 & 0 & 0.8 & 1.3 & 3.1 & 3.5 & 4.2 & 4.8 & 5.2 & 6.0 & 7.6 & 7.9 \\
\hline Formula 3 & 0 & 1.0 & 1.9 & 3.3 & 4.3 & 4.9 & 6.3 & 7.3 & 7.2 & 9.4 & 9.5 \\
\hline $\begin{array}{l}\text { Urea tanpa } \\
\text { penyalut }\end{array}$ & 0 & 13 & 33.7 & 61.5 & 94.9 & 94.9 & 94.9 & 94.9 & 94.93 & 94.9 & 94.9 \\
\hline
\end{tabular}


Pelepasan yang mengikuti model kinetika orde satu, mekanisme pelepasan urea terjadi secara difusi.Jika pelepasan urea mengikuti model kinetika Korsemeyer-peppas berarti pelepasan urea berdasarkan mekanisme difusi Fickian. Sedangkan untuk formula 1, mengikuti model kinetika pelepasan Langenbucher dengan nilai $r$ untuk formula 1 sebesar 0,9927.. Pelepasan urea yang mengikuti model kinetika langenbucher berarti pada saat pelepasan terjadi proses difusi dan erosi pada granul kemudian terjadi akumulasi dalam fraksi larutan yang berarti tidak ada lag time atau pelepasan di awal yang lambat.

\section{Profil Pelepasan Urea Media Tanah}

Hasil aplikasi dari formula 2, 3 dan urea tanpa penyalutan, pada media tanah selama 10 hari aplikasi, memperlihatkan profil pelepasan lambat pada formula 2 dan formula 3. Dimana urea yang terlepas dari formula 2 hanya sebesar $18,3 \%$ dan formula 3 sebesar $28 \%$. Profil kinetika pelepasan pada media tanah, untuk formula 2,3 , mengikuti model kinetika pelepasan orde 0 dan model kinetika pelepasan Korsemeyer-peppas.Dimana nilai koefisien regresi (r) untuk kedua model kinetika pelepasan tersebut paling mendekati, dimana nilai $\mathrm{r}$ untuk formula 2, 3, dengan menggunakan model kinetika pelepasan orde 0 yaitu berturut-turut sebesar $0.9955 ; 0.998$. Sedangkan nilai $r$ untuk formula 2,3 , dengan menggunakan model kinetika pelepasan Korsemeyer-peppas yaitu berturut-turut sebesar 0.9973; 0.9981.

\section{Profil Pelepasan Urea Media Lumpur}

Hasil aplikasi pupuk urea salut bioblend pada media lumpur memperlihatkan profil pelepasan urea yang lebih lambat dibandingkan media air dan tanah. Hasil aplikasi dari formula 2, 3, dan urea tanpa penyalutan, pada media lumpur selama 10 hari, memperlihatkan profil pelepasan yang lebih lambat pada formula 2 dan formula 3 . Persentase urea yang dilepaskan setelah 10 hari aplikasi pada media lumpur, untuk formula 2 dan formula 3 hanya sebesar 7,9\% dan $9,5 \%$.

Profil model kinetika pelepasan pada media lumpur, untuk formula 2mengikuti model kinetika pelepasan orde 0 , dengan nilai $r$ sebesar 0.9780 . Untuk formula 3, mengikuti model kinetika pelepasan Langenbucher dengan nilai $r$ sebesar 0.9929 .

\section{KESIMPULAN}

Hasi penelitian menunjukkan bahwa bioblend polistiren sebagai penyalut urea granul dengan teknik penyalutan semprot memiliki kesesuaian untuk produksi urea lepas lambat, dimana proses dan bahan penyalut sangat mempengaruhi morfologi dan profil pelepasanzat aktif. Profil pelepasan urea granul salut bioblend polistiren memiliki karakteristik sebagai pupuk lepas lambat karena laju pelepasan lebih lambat dibandingkan urea granul tanpa penyalutan

\section{DAFTAR PUSTAKA}

1. R. Lan, Y. Liu, G. Wang, T. Wang, C. Kan, Y. Jin, Experimental modeling of polymer latex spray coating for producing controlled-release urea, Particuology. 9 (2011) 510-516.

2. A. Shaviv, R.L. Mikkelsen, Controlledrelease fertilizers to increase efficiency of nutrient use and minimize environmental degradation - A review, Fertilizer Research. 35 (1993) 1-12.

3. A. Shaviv, S. Raban, E. Zaidel, Modeling Controlled Nutrient Release from Polymer Coated Fertilizers: Diffusion Release from Single Granules, Environ. Sci. Technol. 37 (2003) 22512256.

4. X. Han, S. Chen, X. Hu, Controlledrelease fertilizer encapsulated by starch/polyvinyl alcohol coating, Desalination. 240 (2009) 21-26.

5. M. Tomaszewska, A. Jarosiewicz, Polysulfone coating with starch addition in CRF formulation, Desalination. 163 (2004) 247-252.

6. K. Arata, F.Eiji, H. Tomoji, A Mechanism of Nutrient Release from Resin-Coated Fertilizers and Its Estimation by Kinetic Methods: 2. Release of Nutrients Affected by the Permeability of Water Vapor through Coating Material, Journal of the science 
of soil and manure, Japan. 68 (1997) 1422.

7. A. Shaviv, Advances in controlledrelease fertilizers, in: Academic Press, 2001: pp. 1-49.

8. M. Avella, E. Martuscelli, M. Raimo, Review Properties of blends and composites based on poly(3hydroxy)butyrate (PHB) and poly(3hydroxybutyrate-hydroxyvalerate) (PHBV) copolymers, Journal of Materials Science. 35 (2000) 523-545.

9. S.I. Sempeho, H.T. Kim, E. Mubofu, A. Hilonga, Meticulous Overview on the Controlled Release Fertilizers, Advances in Chemistry. 2014 (2014) e363071.

10. O.A. Salman, Polymer coating on urea prills to reduce dissolution rate, J. Agric. Food Chem. 36 (1988) 616-621.

11. M.M.E. Costa, E.C.M. CabralAlbuquerque, T.L.M. Alves, J.C. Pinto, R.L. Fialho, Use of Polyhydroxybutyrate and Ethyl Cellulose for Coating of Urea Granules, J. Agric. Food Chem. 61 (2013) 9984-9991.

12. A. Djamaan, A.D. Lubis, L.Fitriani, A.P. Dewi, N. Suharti, M. Suardi, E.S. Ben, E. Zaini, Use of biopolymer of polycaprolactone as matrix of verapamilhydrochloride micro-capsule, Journal of Chemical and Pharmaceutical Research. 7 (2015) 683-689.

13. L. Chen, Z. Xie, X. Zhuang, X. Chen, X. Jing, Controlled release of urea encapsulated by starch-g-poly(l-lactide), Carbohydrate Polymers. 72 (2008) 342348.
14. M. Vashishtha, P. Dongara, D. Singh, Improvement in properties of urea by phosphogypsum coating, Int. J. of ChemTech Research. 2 (2010) 36-44.

15. BMKG, Buletin Analisis Hujan Bulan Januari 2014 dan Prakiraan Hujan Bulan Maret, (2014).

16. N. Xiaoyu, W. Yuejin, W. Zhengyan, W. Lin, Q. Guannan, Y. Lixiang, A novel slow-release urea fertiliser: Physical and chemical analysis of its structure and study of its release mechanism,Biosystems Engineering. 115 (2013) 274-282.

17. T. Zheng, Y. Liang, S. Ye, Z. He, Superabsorbent hydrogels as carriers for the controlled-release of urea: Experiments and a mathematical model describing the release rate, Biosystems Engineering. 102 (2009) 44-50.

18. [C.L. O'Neal, D.J. Crouch, A.A. Fatah, Validation of twelve chemical spot tests for the detection of drugs of abuse, Forensic Science International. 109 (2000) 189-201.

19. X. He, Z. Liao, P. Huang, J. Duan, R. GE, H. LI, et al., Characteristics and Performance of Novel Water-Absorbent Slow Release Nitrogen Fertilizers, Agricultural Sciences in China. 6 (2007) 338-346.

20. L. Xie, M. Liu, B. Ni, X. Zhang, Y. Wang, Slow-release nitrogen and boron fertilizer from a functional superabsorbent formulation based on wheat straw and attapulgite, Chemical Engineering Journal. 167 (2011) 342348. 